\title{
A CONSTRUÇÃO DE NARRATIVAS HISTÓRICAS: CONSERVAÇÃO DA MEMÓRIA NA TERCEIRA IDADE
}

\author{
Érica Fernanda Zavadovski KALINOVSKI ${ }^{1}$ \\ Fabiane Freire FRANÇA ${ }^{2}$
}

RESUMO: Este artigo tem por objetivo compreender a necessidade de atividades voltadas à memória na terceira idade, por meio da construção de narrativas históricas orais. Pautamo-nos na prática de estágio supervisionado, na modalidade de educação não formal ${ }^{3}$, desempenhada em um centro de atendimento ao idoso, a fim de apresentar o Trabalho de Conclusão de Curso da graduação em Pedagogia no ano de 2014. Partimos da seguinte indagação: como é possível estimular e conservar a memória de idosos a partir da produção de narrativas orais baseadas em fatos históricos de suas vidas? Assim, verificamos a relevância de idosos manterem uma boa saúde mental. Concluímos que: a) as instituições destinadas a idosos precisam ultrapassar o trabalho assistencialista e funcional; b) parte dos idosos se sentiu um tanto desmotivados ao terem de relembrar ações passadas de suas vidas; c) é preciso incitar e sustentar a memória nessa e, em todas as fases vitais.

PALAVRAS-CHAVE: Educação não formal. Narrativas orais. História. Memória. Idoso.

\section{INTRODUÇÃO}

Com base nos estudos referentes à terceira idade, destaca-se a relevância de compreender os elementos que envolvem a educação voltada a essa população. Isso porque, cabe às instituições que destinam atendimento a esse público, não apenas realizar um trabalho assistencialista e/ou técnico, mas, devem, sobretudo, contribuir para o desenvolvimento e aperfeiçoamento das capacidades cognitivas e pensantes dos idosos.

Diante disso, esse trabalho foi desenvolvido em decorrência do desenvolvimento da prática de estágio voltada à educação não formal, a qual foi desempenhada em um Centro de Convivência do Idoso (CCI), cuja intenção foi propor a idosos possibilidades de manutenção da saúde mental, fazendo-os perceber que é fundamental estimular a memória e instigar o pensamento para que se tenha qualidade de vida.

\footnotetext{
${ }^{1}$ Mestranda em Estudos Linguísticos. UEM - Universidade Estadual de Maringá. Programa de PósGraduação em Letras. Maringá - PR - Brasil. 87020-900 - ericafzk@ gmail.com

2 Professora adjunta. UNESPAR - Universidade Estadual do Paraná. Campo Mourão - PR - Brasil. 87302-060 - prof.fabianefreire@gmail.com

${ }^{3}$ Atualmente, parte dos estudiosos dessa modalidade da educação, a denominam de educação não escolar, porém, por utilizarmos referencial teórico em que permanece a nomeação educação não formal (GOHN, 2006; TRILLA, 2008), decidimos não realizar essa distinção e manter o termo dos autores.
} 
Para melhor entendimento do assunto, o trabalho está organizado do seguinte modo: inicia-se com uma exposição das formas de educação, delineadas por Gohn (2006) e Trilla (2008), com ênfase à educação não formal: Os caminhos para a educação: reflexões iniciais acerca do espaço não formal. Na segunda parte, intitulada Educação não formal na terceira idade, apresenta-se uma breve caracterização da velhice, com base no Estatuto do Idoso (BRASIL, 2006) e, inclusive, a visão que normalmente é tida sobre esse grupo, tal como enfatiza Gomes (2012) e, na sequência, também será discorrido sobre a contribuição que essa forma de educação pode exercer para a vida do idoso, com a inserção, por exemplo, de narrativas históricas orais (PESAVENTO, 2006) em suas práticas e a necessidade da estimulação psíquica, com base em Zimerman (2000). Na terceira parte, denominada Terceira idade e a construção de narrativas históricas orais: percursos metodológicos, descrevem-se os caminhos metodológicos da prática que foi realizada com os idosos, durante o estágio, relatando e refletindo teoricamente os procedimentos utilizados. Por fim, em Análise dos resultados, apresenta-se o exame do material coletado e as conclusões obtidas no processo.

\section{OS CAMINHOS PARA A EDUCAÇÃO: REFLEXÕES INICIAIS ACERCA DO ESPAÇO NÃO FORMAL}

A educação sempre esteve presente na vida dos seres humanos, no entanto, nem sempre foi concebida do mesmo modo. Para Gohn (2006), admite-se hoje, três categorias que a envolvem: a educação formal, a educação informal e a educação não formal. Cada uma delas apresenta sua importância, de forma que devem se complementar e não serem vistas como um modo de privilegiar uma em detrimento de outra ou, ainda, como forma de substituição.

É evidente que o processo de ensino e aprendizagem são fenômenos complexos e não acontecem apenas nos ambientes ditos escolares, portanto, recebemos vários tipos de educações: "a dos pais, ou familiar; a dos mestres, ou escolar, e a 'do mundo' [...]: a chamada educação não-formal" (TRILLA, 2008, p.16).

Em se tratando da educação formal, destaca-se que ela se caracteriza por sua organização e sistematização, sendo que, é exclusivamente escolar e, diante disso, apresenta um espaço físico próprio, tempo previamente estipulado, conhecimentos historicamente constituídos, entre outros fatores que a designam. Nesse sentido, Gohn 
(2006, p.28) salienta que "a educação formal é aquela desenvolvida nas escolas, com conteúdos previamente demarcados", cujo responsável por exercer essa função, é o professor.

Já a educação informal é aquela que ocorre nas várias instâncias da sociedade, de maneira espontânea, pois não tem uma intencionalidade explícita. Esse modo de educar ocorre socialmente, seja na família, no clube, etc., e tem valores e culturas específicas que partem de sentimentos herdados (GOHN, 2006). Além disso, “[...] na educação informal, os agentes educadores são os pais, a família em geral, os amigos, os vizinhos, colegas de escola, a igreja paroquial, os meios de comunicação de massa, etc." (GOHN, 2006, p. 29).

Por fim, a educação não formal pode ser vista como uma medida complementar, sobretudo, à educação escolar, uma vez que, no decurso da história houve a

[...] necessidade de criar, paralelamente à escola, outros meios e ambientes educacionais. Meios e ambientes que, claro, não devem ser vistos necessariamente como opostos ou alternativos à escola, mas como funcionalmente complementares a ela. Esses recursos são, em grande medida, justamente aqueles que a partir de certo momento passaram a ser chamados de "não-formais" (TRILLA, 2008, p.18, grifo do autor).

Na modalidade de educação não formal, também é possível verificar uma intencionalidade, e é desenvolvida em algumas instâncias específicas, tais como Centros de Integração Social, Bibliotecas, Centros de Convivência do Idoso, Asilos, Presídios, Hospitais, etc. Gohn (2006) destaca que o educador na educação não formal, corresponde ao "outro", portanto, é a pessoa com quem se interage, sejam os amigos, os vizinhos, a própria família.

A partir do breve entendimento a respeito das educações formal, informal e não formal, é preciso ressalvar que, “[...] mesmo que nem sempre estejam ligadas orgânica ou explicitamente, estão fundamentalmente relacionadas. Essas relações funcionais podem dar-se - como de fato se dão - de maneiras muito diversas." (TRILLA, 2008, p.46).

Diante da compreensão de que constantemente aprende-se, uma vez que a educação se apresenta de diversas maneiras e em várias instâncias da sociedade, é preciso considerar que os idosos também estão inseridos nesse processo e, que é possível e necessário que aprendam diariamente. A seguir, realizar-se-á uma breve 
discussão acerca da denominada melhor idade, e como pode-se integrar a educação não formal a essa população.

\section{EDUCAÇÃO NÃO FORMAL NA TERCEIRA IDADE}

Conforme já evidenciado, as instituições que desenvolvem trabalhos com a terceira idade, como os Centros de Convivência do Idoso (CCIs), também podem caracterizar-se por serem voltadas à educação não formal. Vale ressaltar que esses estabelecimentos não devem ter somente um cunho assistencialista em sua prática, dando ênfase apenas às técnicas de artesanato, música ou dança, mas, precisam, acima de tudo, ter a intenção de contribuir para a manutenção e desenvolvimento dos processos cognitivos desses sujeitos, proporcionando a interação e a socialização.

Como prevê o Artigo $1^{\circ}$ do Estatuto do Idoso (BRASIL, 2006, p.7), é considerado pertencente a essa etapa da vida, sujeitos com idade igual ou superior a 60 (sessenta) anos. Além disso, a terceira idade é concebida como a última fase da vida ${ }^{4}$ que marca o nosso ciclo vital. Assim,

[...] envelhecer pressupõe alterações físicas, psicológicas e sociais no indivíduo. [...] essas transformações são gerais, podendo se verificar em idade mais precoce ou mais avançada e em menor ou maior grau, de acordo com as características genéticas de cada indivíduo e, principalmente com o modo de vida de cada um. A alimentação adequada, a prática de exercícios físicos, [...] a estimulação mental, [...] são alguns fatores que podem retardar ou minimizar os efeitos da passagem do tempo. (ZIMERMAN, 2000, p.21).

Além do mais, para Bezerra (2006, p.7), existem várias denominações da pessoa idosa, dentre elas: “[...] 'pessoa da terceira idade', 'pessoa da melhor idade', 'velhos', 'pessoa de meia-idade', 'maior idade', 'idade madura', 'idade avançada', entre várias outras." A autora destaca, no entanto, que apesar das diferentes expressões utilizadas para nomear as pessoas com sessenta anos de idade ou mais, "o importante é que sejam empregadas sem que ofendam a dignidade e o respeito ao idoso" (BEZERRA, 2006, p.7).

\footnotetext{
${ }^{4}$ Atualmente, há estudos que questionam o fato de a terceira idade ser a última fase da vida, por haver, pelo menos, uma, que a sucede. Porém, isso não será discutido em virtude do objetivo do artigo.
} 
Todavia, Gomes (2012) destaca que, no Brasil, existem diferentes tipos de discursos preconceituosos expressos pela sociedade e veiculados pela mídia. A autora enfatiza que,

[...] tais discursos narram os idosos como seres invisíveis na sociedade, marcados pela ação do tempo e dotados de conhecimentos que pouco interessam ao mundo, o qual se mostra cada vez mais tecnológico. Distantes e não conhecedores das atuais ferramentas de conexão humana, os idosos apresentam-se como presa fácil para as doenças físicas e mentais que naturalmente acometem seu grupo etário. (GOMES, 2012, p.17).

Em vista disso, Gomes (2012) ressalta a importância e a necessidade de se desmistificar tal visão negativa e estereotipada dos sujeitos pertencentes à terceira idade. Para isso, é necessário compreender os mecanismos que podem contribuir para o desenvolvimento da velhice de maneira significativa para sua faixa etária.

Ressalta-se que tem havido o aumento da população em decorrência da queda da mortalidade, das conquistas médicas, do avanço nutricional, da elevação dos níveis sócio econômicos, bem como da melhoria da qualidade de vida, entre outros, o que conduz ao aumento da expectativa de vida. Conforme afirma Néri (2004, p.71),

[...] no Brasil, nos últimos sessenta anos, houve expressiva evolução da expectativa de vida por ocasião do nascimento: em 1900, girava em torno de 34 anos; em 1940, era de 39; em 1960, 41; em 1970, 59; em 1980 e 1990, 61. Estima-se que será [...] de 75 em 2020.

Com isso, é preciso que haja criação e efetivação de políticas públicas que atendam as peculiaridades desse grupo social. Considera-se fundamental o trabalho com os idosos voltado ao estímulo da memória, pois, por meio dela, o ser humano tem a capacidade de aprender novos conhecimentos durante todo o seu desenvolvimento, resolver problemas simples e complexos e relacionar-se com os outros, pois "estimular, entre outras coisas, quer dizer excitar, incitar, instigar, ativar, animar, encorajar" (ZIMERMAN, 2000, p. 133).

Nesse caso, é preciso desempenhar a estimulação da pessoa da terceira idade, voltada para “[...] a inteligência, a memória, a capacidade de aprendizagem, os relacionamentos, os pensamentos, a auto-estima, enfim, os aspectos da esfera socioemocional.” (ZIMERMAN, 2000, p.134), uma vez que, quando nos referimos à estimulação, muitos a concebem “[...] apenas como exercícios físicos [...]. A maioria só 
faz exercícios para fortalecer os músculos, para melhor condicionar as articulações, como se cuidar da saúde fosse apenas preocupar-se com o físico." (ZIMERMAN, 2000, p.134).

Para a realização deste trabalho, conforme supramencionado, foi desenvolvida uma prática em um CCI, o qual oferece educação não formal à idosos. Selecionou-se esse local, por compreender a importância da contribuição do desenvolvimento cognitivo, pensante, discursivo e linguístico, também, nessa etapa da vida.

Para tanto, será demonstrada adiante, como foi realizada a incursão com os idosos e a forma como adotou-se as narrativas históricas orais como mote para a concretização dessa proposta, que compreendeu a incitação e a permanência da memória, bem como o reconhecimento das histórias de vida como parte de uma história maior, em que estão presentes relações de temporalidade, discorridas em Pesavento (2006), Bergamaschi (2011) e Paraná (2008), com ênfase nas mudanças e permanências; relações de trabalho e condições sociais e relações de poder.

Com isso, este estudo teve a intenção de contribuir para a incitação e manutenção da memória na terceira idade, por meio de alguns procedimentos que possibilitaram o desenvolvimento desse trabalho, conforme será apresentado a seguir.

\section{TERCEIRA IDADE E A CONSTRUÇÃO DE NARRATIVAS HISTÓRICAS ORAIS: PERCURSOS METODOLÓGICOOS}

Para a efetivação dessa proposta, de natureza qualitativa, foi desenvolvido um trabalho voltado à importância da conservação da memória na melhor idade, a partir da metodologia da história oral, com o uso de fotografias. Para tanto, o grupo em que realizamos esse projeto, era composto por 16 pessoas $^{5}$, todas mulheres, entre 56 e 82 anos de idade. Tiveram quatro encontros, totalizando uma carga horária de 20 horas, no decorrer do ano de 2014.

Entre as modalidades da narrativa oral, (de vida; temática; tradição oral), nos pautamos na história oral de vida, em que o entrevistado tem liberdade para expor a narrativa das trajetórias de sua biografia, sendo que,

[...] priorizar as narrativas da memória, em história oral, significa produzir narrativas de identidade, à medida que o sujeito revela como

\footnotetext{
${ }^{5}$ Nem todas estavam presentes em todos os encontros, por diversos motivos, como pelo fato de algumas delas morarem distante do CCI e não poder participar de todos os encontros.
} 
vê a si mesmo e como vê o mundo [...] Desse modo, produzir a narrativa oral, individualizada de cada sujeito, é produzir uma história social; é transpor os limites de um estudo de caso, reconhecendo os vínculos com os múltiplos aspectos da vivência coletiva. (HAAS, 2012, p.13).

O sujeito coloca-se como produtor de sua história, resgata lembranças de forma seletiva, traz de volta lembranças do passado e o reconstrói conforme suas necessidades.

Além do mais, ao se trabalhar com história oral é preciso considerar "a relevância dos relatos orais como um documento" (LOPES-GOMES, 2007, p.11) e não como algo sem validade científica.

Desse modo, conforme Hass (2012), utilizamos a metodologia de história oral, por considerar que a memória também se trata de uma fonte de produção de conhecimento, pois “[...] a atribuição de significado às memórias pelos sujeitos ou as distinções processadas pelo sujeito na visitação às suas memórias compõem o alicerce para alinhavar uma conversação em mesmo ou em distinto domínio linguístico." (HAAS, 2012, p.14).

Assim, ao trabalhar as narrativas históricas orais com os idosos, objetivamos que elas retomassem lembranças do passado (não necessariamente distantes), que "é trazido para o presente, reconstruído, em uma operação imaginária de sentido" (PESAVENTO, 2006, p.5).

Isso porque, na Política Nacional do Idoso considera-se que

[...] a promoção do envelhecimento saudável e a manutenção da máxima capacidade funcional do indivíduo que envelhece, pelo maior tempo possível - foco central desta Política -, significa a valorização da autonomia ou autodeterminação e a preservação da independência física e mental do idoso. (BRASIL, 1999, p.6).

As atividades práticas do estágio, nessa modalidade de educação não formal, foram organizadas da seguinte forma: iniciamos com uma abordagem acerca do assunto selecionado, demonstrando a relevância de manter uma boa saúde mental. Na sequência, transmitimos o filme Narradores de Javé, a fim de que percebessem como diferentes pessoas contam histórias semelhantes ou distintas e peculiares, mas que, ainda assim, se relacionam entre si, já que "[...] o tempo é uma construção sociocultural, que se apresenta de distintas formas na sociedade desde épocas remotas e que modula a vida das pessoas de diferentes maneiras." (BERGAMASCHI, 2011, p.3). 
Com isso, foi possível proporcionar a reflexão, ainda, sobre a importância de ser alfabetizado (como maneira de estimular a memória e outras funções cognitivas) aspecto que também esteve presente no filme, tendo em vista que o grupo participante desse projeto também frequentava o programa Paraná Alfabetizado ${ }^{6}$ que, da mesma forma, é ofertado no CCI.

Enfatizamos que para conhecer a história do outro, é importante saber, inicialmente, o nome da pessoa com quem interagimos. Com isso, foram listados os nomes de todas as integrantes da pesquisa para maior reconhecimento umas das outras, solicitando que cada uma fosse dizendo o nome de alguma colega do grupo até que todas se reconhecessem.

Nesse momento, notamos que, apesar de conviverem juntas há oito meses, aproximadamente, em decorrência das atividades que são ofertadas na instituição, como é o caso do Programa Paraná Alfabetizado, muitas não se recordavam do nome das demais colegas, apenas das mais próximas a elas. Essa atividade, da mesma maneira, proporcionou um estímulo a lembrança, quando possível, dos nomes.

Em seguida, abordamos, mais especificamente, acerca dos benefícios que a retomada histórica de suas próprias vivências pode representar para a manutenção da memória, considerando que,

[...] é preciso enfrentar o seu reverso - o esquecimento - e ter em conta que a memória é uma contínua reconstrução, renovadamente a preencher lacunas e vazios com as lembranças de terceiros ou a refazer a narrativa conforme as reavaliações feitas ao longo da existência (PESAVENTO, 2006, p.6).

Além disso, "a memória é um elemento essencial do que se costuma chamar identidade, individual ou coletiva" (LE GOFF, 1990, p.410, grifo do autor) e, como tal, precisa ser instigada e preservada.

No mesmo dia, informamos que no encontro seguinte iríamos encenar uma história e, posteriormente, realizar uma roda de conversa, mas, para isso, seria interessante que elas apresentassem algumas fotografias para narrarem suas histórias. Portanto, solicitamos que separassem algumas fotos e levassem no próximo encontro.

${ }^{6}$ O programa Paraná Alfabetizado é uma forma de preparo para a Educação de Jovens e Adultos (EJA). $\mathrm{Na}$ instituição em que desenvolvemos o estágio, ela é destinada à senhoras entre 56 a 82 anos de idade, um grupo de aproximadamente 16 pessoas. Destacamos que o trabalho foi desenvolvido nessa turma, no entanto, não contemplamos, nesse momento, a prática de alfabetização, mas sim, a realização do estágio na modalidade de educação não formal. 
Desse modo, ao realizarmos a encenação adaptada da história $A$ colcha de retalhos (SILVA; SILVA, 2010), tivemos a intenção de reforçar as diferentes histórias e suas relações.

Em seguida, refletimos com o grupo o conteúdo da encenação, a mensagem que buscamos transmitir com base no texto original, quando foi demonstrado que, assim como uma colcha de retalhos, é possível visualizar resquícios de diversas histórias e momentos marcantes na vida de uma pessoa, que nossa própria vivência também está marcada por diversas e, por vezes, diferentes histórias, que podem, ou não, se relacionar umas com as outras.

Assim, falas durante a encenação, como quando a personagem da neta disse: Olha esse pano listrado, é daquele pijama que a senhora fez para mim quando a gente passou aqueles dias no sítio, lembra?, ou, quando a personagem da vovó afirmou: É daquela camisa que eu fiz para você dar ao seu pai, no dia do aniversário dele. Sua mãe fez um jantar gostoso e convidou todo mundo, demonstram que um objeto pode remetermo-nos a situações vividas, as quais podem ser relembradas e, por isso, apresentam uma relação temporal (PESAVENTO, 2006; PARANÁ, 2008, BERGAMASCHI, 2011).

Isso possibilitou a visualização, de maneira mais concreta, de que os acontecimentos que nos envolvem, também fazem parte de uma história e, portanto, temos a possibilidade e a necessidade de resgatá-las, seja quando e/ou como for. Nesse sentido, foram organizadas algumas categorias de análise: 1) relações de trabalho e condições sociais; 2) relações de poder e 3) mudanças e permanências.

Após fazermos alguns apontamentos, foi possível iniciar uma roda de conversa, sendo que, conforme solicitamos, as senhoras participantes da prática de estágio deveriam narrar um fragmento marcante de sua vida, de modo que pudéssemos visualizar, por meio de suas fotografias, conforme representado na imagem a seguir: 
Figura 1 - Exposição das fotos e roda de conversa

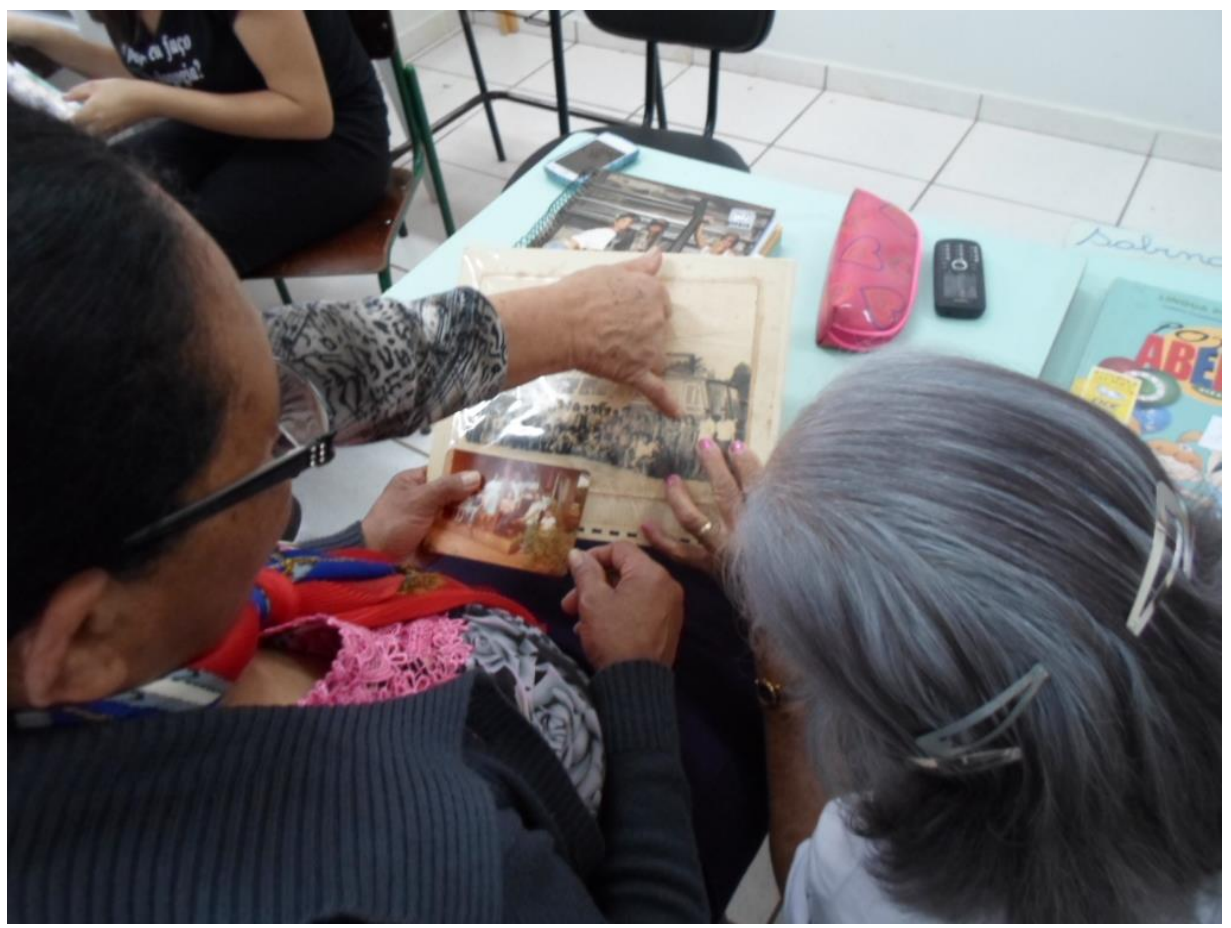

Fonte: Arquivo pessoal, 2014.

Nem todas as integrantes do grupo levaram as fotografias, conforme pedimos, no entanto, a maioria realizou seu relato, ainda que sem nos mostrar as fotos, demonstrando, em alguns momentos, certa angústia e anseios ao se recordarem de alguns episódios, considerados por elas, como trágicos ou negativos. Isso ocorreu, especialmente, porque parte delas atribuiu a noção de tempo histórico apenas a episódios antigos e distantes, todavia,

[...] toda a história é bem contemporânea, na medida em que o passado é apreendido no presente e responde, portanto, aos seus interesses, o que não é só inevitável, como legítimo. Pois que a história é duração, o passado é ao mesmo tempo passado e presente (LE GOFF, 1990, p.41).

Portanto, para o exame do material coletado, conforme apresentaremos a seguir, pautamo-nos nas já referidas categorias de análise, de forma que, a relação de trabalho e condições sociais dizem respeito às determinações sociais e de vida de uma dada população, pois, o trabalho pode ocorrer tanto entre os seres humanos com si próprios quanto com a natureza e, ele é uma condição para a vida humana. Atrelada a isso, temse a relação de poder, pois como vivemos em uma sociedade cujo modo de produção é capitalista, a própria relação de trabalho e condições sociais decorrem das relações de 
poder. As mudanças e permanências, por sua vez, marcam todo esse processo, já que, no decorrer do tempo, todas essas relações são passíveis de mudanças e ressignificações.

\section{ANÁLISE DOS RESULTADOS}

Diante do exposto, passaremos a analisar as narrativas históricas do grupo em estudo, a partir das categorias mencionadas anteriormente.

Foi possível verificar que algumas falas das senhoras remeteram-se às relações de trabalho e às condições sociais, como quando uma delas demonstrou uma de suas fotografias e narrou: Aquela foto alí, ó, é lembrança das minhas filhas. Eu tenho três filha mulher e, a mais velha foi pra Curitiba [...] sem ter distino, mas, quando chegou lá, dormiu até na rua, dormiu na porta da Igreja muitas vezes, aí eu ficava doente de pensar. Mas, um dia, ela achou uma mulher e a mulher disse, não, vai trabalhar pra mim. Ela saiu procurar trabalho, né? Aí, não, vai trabalhar pra $\mathrm{mim}^{7}$.

Esse fragmento de narrativa evidencia, portanto, a situação a que uma das filhas da senhora precisou passar, atrelada, ainda, à relação de trabalho, quando, em meio a condição social em que ela se encontrava, conseguiu um emprego, isso porque "as relações de trabalho permitem diversas formas de organização social” (PARANÁ, 2008, p.64).

Notamos, também, relações de poder, vinculadas às relações de trabalho e influências culturais, pois “[...] o estudo das relações de poder geralmente remete à ideia de poder político. Entretanto, elas não se limitam somente ao âmbito político, mas, também, nas relações de trabalho e cultura" (PARANÁ, 2008, p.66). Como quando uma das senhoras afirmou: Meu pai foi até preso por causa dessa terra aí, mas a gente não desistiu, aí a polícia disse, não, você tem que mostrar que você trabalha.

Outras demonstraram em suas falas e fotografias, mudanças e permanências: $E u$ fui morar perto de uma senhora, daí ela falava pra mim assim: - Larga desse homem, esse home tá te ajudiando, esse home fica só no baraio e eu fui ponhando aquilo na minha cabeça, eu tenho que largar desse homem. Daí descobri que ele tinha as muié [...] daí eu falei, não, tenho que largar desse home. Mas, ele ia embora, mas voltava. [...] E, agora, por último [...] eu fiquei, nóis separado dele 35 anos, mas só que ele não

\footnotetext{
${ }^{7}$ Todas as histórias orais foram transcritas conforme relatadas. Para sua identificação, os fragmentos das narrativas estão grafadas em itálico.
} 
me dava paz, ele vivia cas outras mulher, mas chegava na minha casa metia o pé na porta assim [...] quebrava tudo a minhas coisas, não dava comida. [...] Daí, ele disquito, passo alí, quinze dias ele foi pra UTI, daí vieram atrás de mim [...] Daí eu fui, né? [...] Daí ele falou pra mim assim: - Você me perdoa pelas coisas tudo errada que eu fiz? Eu to sofrendo pela ruindade que eu era.

Nessa narrativa, percebemos que, “[...] o tempo produz suas marcas obedecendo a um ritmo lento, sem desconsiderar a existência de diferentes ritmos nas transformações históricas.” (BERGAMASCHI, 2011, p.8), pois todas essas marcas de temporalidade presentes na fala da senhora evidenciam que foi necessário um longo período para que as mudanças e permanências se concretizassem.

Da mesma forma, a fala seguinte, evidencia mudanças e permanências, quando a senhora narrou: Eu casei, mas casei aqui no Paraná, porque meu pai não deixava eu casar. Sou de Ilhéus, é, Bahia. [...] E eu era muito presa [...] eu saí de lá com 20 anos e, eu não podia namorar. [...] Aí eu vim pro Paraná, no mesmo ano que eu vim no Paraná, eu casei. [...] eu vim nova de lá e eu num voltei mais lá. [...] e eu fiquei aqui com o meu marido.

Verificamos as mudanças que marcaram a vida dessa senhora, especialmente no momento em que ela se muda de Estado e, quando, em um primeiro momento, casar-se, para ela, era algo reprimido, mas logo que vem para o Paraná, ela se casa. Em contrapartida, visualizamos permanências, pois, desde quando ela se mudou para o Paraná, ainda continua aqui e, do mesmo modo, por nunca mais ter voltado para a Bahia.

Todas as narrativas marcaram, de alguma forma, as categorias que elencamos, tendo em vista que os fatos históricos sempre apresentam relações de poder, de trabalho e condições sociais e, também, relações de temporalidade, que assinalam mudanças e permanências, semelhanças e diferenças ao longo do tempo, pois, diferente da tradicional " [...] racionalidade histórica orientada pela linearidade dos fatos, pelo uso restrito dos documentos oficiais como fonte e verdade histórica e, por fim, pela perspectiva da valorização política dos heróis.” (PARANÁ, 2008, p.38), consideramos que todos temos e fazemos parte da história.

Ao desenvolver essa prática de diálogo com as senhoras, tivemos a intenção de fazê-las perceberem o quão importante é preservar a memória ativa, possível, entre outras formas, por meio de recordações de suas próprias histórias, uma vez que, para Le Goff (1990), 
[...] a memória, como propriedade de conservar certas informações, remete-nos em primeiro lugar a um conjunto de funções psíquicas, graças às quais o homem pode atualizar impressões ou informações passadas, ou que ele representa como passadas. (LE GOFF, 1990, p.366).

Ademais, conforme Pesavento (2006, p.1), "História e memória partilham uma mesma feição de ser: são ambas narrativas, formas de dizer o mundo, de olhar o real. São discursos, pois. Falas que discorrem, descrevem, explicam, interpretam, atribuem significados à realidade" que não podem ser ignorados em nenhuma etapa da vida e, sobretudo, na terceira idade.

Ao final dessa intervenção, sugerimos que elas representassem um fragmento marcante de suas vidas, em forma de desenho e/ou a própria escrita, tendo em vista a confecção de uma Colcha de retalhos - com base na encenação - a qual denominamos Colcha de relatos, cujo propósito foi enfatizar as diversas histórias que existem e como todas elas reservam importância especial, seja para elas ou para outras pessoas de seu convívio.

Figura 2 - Colcha de relatos

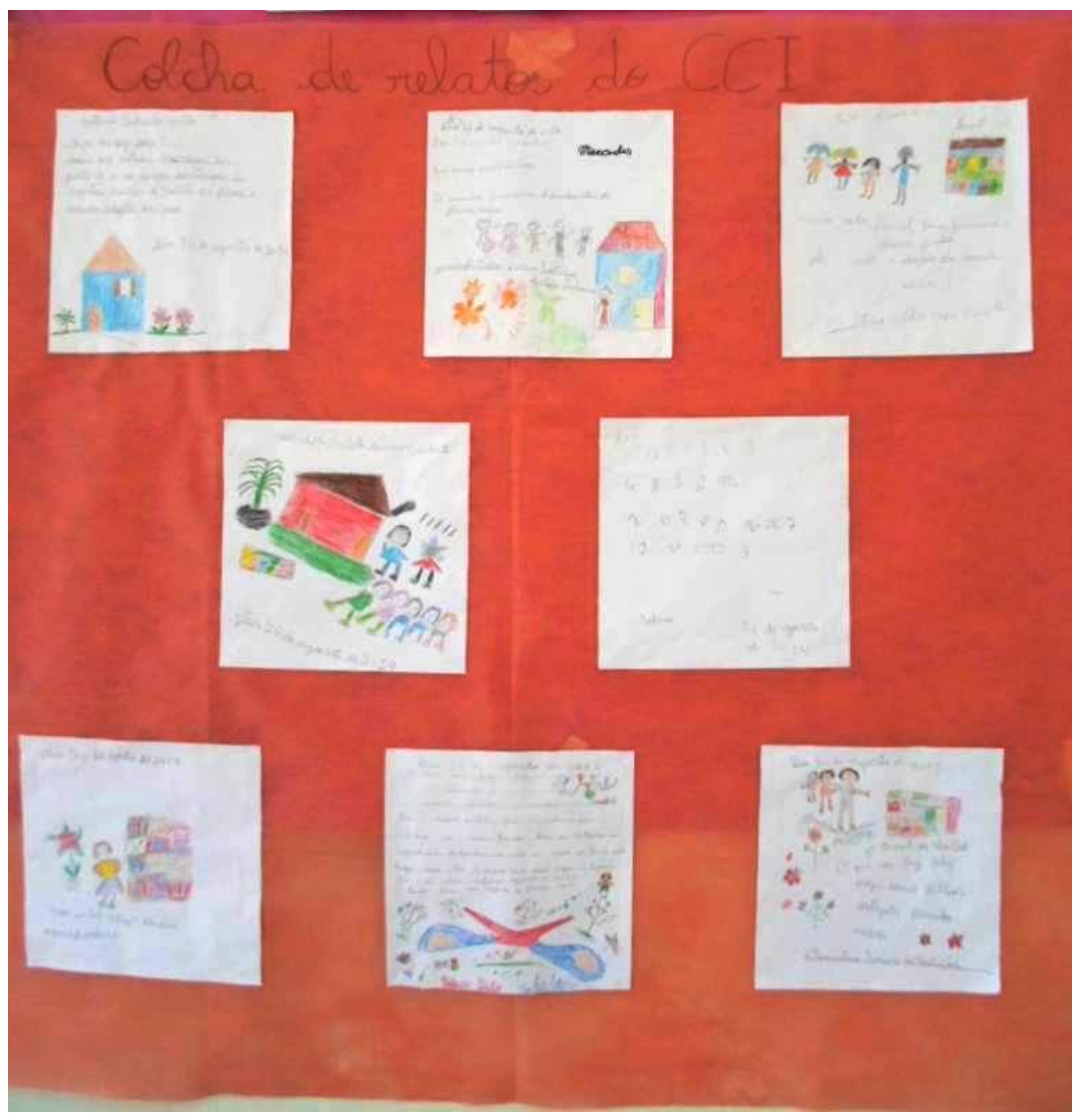

Fonte: Arquivo pessoal, 2014. 
Destacamos que, de início, quando propomos que desempenhassem essa atividade, algumas se recusaram realizar, especialmente por ser voltada ao desenho, acreditando que elas precisavam aprender a ler e a escrever (por vincularem a atividade ao programa de alfabetização). No entanto, ressaltamos que não é apenas a escrita que contribui para a permanência da memória, mas, representações gráficas, ilustrativas e outras, também podem proporcionar esse estímulo. Ainda assim, não negamos o desenvolvimento da atividade de maneira escrita e, ao dizermos que elas também poderiam assim representar, com o nosso auxilio, desenvolveram a atividade.

Verificamos que a grande maioria representou sua família, destacando a importância que ela exerce para sua vida. Quando escreveram, também demonstraram isso, como a seguinte produção: Eu amo a minha família. A minha família é importante para $\mathrm{mim}^{8}$. Ou quando outra senhora afirmou: Meus netos [...] eles são a razão da minha vida!

Nesse sentido, percebemos que a família é considerada pelas senhoras, como essenciais, e que são o alicerce para suas vidas. Essa atividade despertou no grupo um sentimento de saudade, de amor, de compreensão da importância que sua família possui para cada uma e, ainda, a visualização de que há, "mudanças e permanências nos hábitos, costumes, regimes políticos e sistemas econômicos” (PARANÁ, 2008, p.73), nos diferentes contextos e em determinadas épocas.

\section{CONSIDERAÇÕES FINAIS}

Diante do exposto, bem como a partir da prática de estágio supervisionado que foi desenvolvida, constata-se a necessidade que os idosos têm de manter a memória ativa. Nesse sentido, a educação não formal se constitui como um relevante meio de proporcionar a manutenção e a permanência da memória nessa etapa da vida.

A terceira idade é um período em que grandes modificações ocorrem, seja em nível físico e/ou cognitivo e, junto a essas transformações, existem, também, muitas formas preconceituosas de lidar com os idosos. Isso contribui para a desmotivação, o sentimento de que já fez tudo e que, por isso, não serve para mais nada, e todas as

\footnotetext{
${ }^{8}$ As produções foram transcritas conforme as senhoras escreveram. Para sua identificação, todas as produções estão grafadas em itálico.
} 
visões negativas que corroboram para a baixa autoestima dessa população e, consequentemente, para o aparecimento de novos problemas físicos e/ou psicológicos.

Por meio do estudo foi realizado, reconhece-se que esse é um fato recorrente no cenário brasileiro e, nesse sentido, é preciso que, cada vez mais, sejam realizadas práticas que se voltem à contribuição da melhoria de vida dos idosos, por começar na estimulação e na conservação da memória.

Para que isso fosse possível, neste trabalho, desenvolveram-se algumas atividades a fim de que possibilitassem instigar a memória e, assim, conduzir a uma maior percepção, por parte do grupo, de como é importante e necessário fazer exercícios para a memória, constantemente.

O trabalho desempenhado utilizou a construção de narrativas históricas orais, de modo que viabilizasse a retomada de suas trajetórias, a partir de um recurso que, nesse caso, foi a fotografia. Apesar de não ter tido um longo período para o desenvolvimento dessa prática, porém, foi possível perceber que essa intervenção possibilitou, ao menos, que as senhoras resgatassem parte de suas trajetórias, percebessem que elas também possuem e fazem parte da história e que cada uma tem vivências diferentes e, por vezes, semelhantes.

\title{
BUILDING HISTORICAL NARRATIVES: PRESERVATION OF MEMORY IN THE THIRD AGE
}

\begin{abstract}
This article aims to comprehend the need for activities related to memory in the third age, through the construction of oral historical narratives. Using as a referential, the practice of supervised training, in non-formal ${ }^{9}$ education modality, which was performed at a senior care center. It was performed with the purpose to present the coursework in Pedagogy Graduation in 2014. Starting with the following question: how could be possible to encourage and retain elderly memory starting from the production of oral narratives based on historical facts of their lives? Thus, it is confirmed the relevance of elderly people maintaining a good mental health. From this, it is possible to conclude that: a) the institutions aimed to cater the elderly people need to overcome the welfare and functional work; b) part of the elderly felt somewhat discouraged by having to remember past actions of their lives; c) it is necessary to induce and sustain their memory in all vital phases.
\end{abstract}

KEYWORDS: Non-formal education. Oral Narratives. History. Memory. Elderly.

${ }^{9}$ Currently, some of the scholars of this type of education call it non-school education, however, as we use a theoretical framework in which the appointment remains non-formal education (GOHN, 2006; TRILLA, 2008), we decided not making this distinction and we keep the term of the these authors. 


\section{REFERÊNCIAS}

BERGAMASCHI, M. A. O tempo histórico no ensino fundamental. In: HICKMANN, R. Estudos Sociais: outros saberes e outros sabores. 3.ed. Porto Alegre: Mediação, 2011. p.21-23.

BEZERRA, R. M. N. Art. $1^{\circ}$ - Instituição do Estatuto do Idoso e conceito de idoso. In: PINHEIRO, N. M. (Org.). Estatuto do Idoso comentado. São Paulo: LNZ, 2006.

BRASIL. Portaria ${ }^{\circ} 1.395$, de 10 de dezembro de 1999. Diário Oficial [da] República Federativa do Brasil. Brasília, DF, 13 dez. 1999. p.1-24. Política Nacional do Idoso.

Estatuto do idoso: lei federal $\mathrm{n}^{\circ} 10.741$, de 01 de outubro de 2003. 2.ed. Brasília, DF: Ministério da Saúde, 2006.

GOHN, M. da G. Educação não-formal, participação da sociedade civil e estruturas colegiadas nas escolas. Ensaio: Avaliação e Políticas Públicas em Educação, Rio de Janeiro, v.14, n.50, p.27-38, jan./mar. 2006.

GOMES, I de O. Narrativas fílmicas na educação para a velhice. $2012.135 \mathrm{f}$. Dissertação (Mestrado em Educação) - Programa de Pós-Graduação em Educação, Universidade Estadual de Maringá, Maringá, 2012.

LOPES-GOMES, A. As narrativas orais na reconstituição da memória radiofônica: um estudo de caso. Biblioteca On-line de Ciências da Comunicação, v.2007, p.1-23, 2007.

HAAS, C. A história oral como itinerário de pesquisa na Educação Especial: a aceitação do outro como legítimo outro. In: ANPED SUL - SEMINÁRIO DE PESQUISA EM EDUCAÇÃ̃ NA REGIÃO SUL, 9., 2012, Caxias do Sul. Anais... Caxias do Sul, RS: Ed. da UCS, 2012.

LE GOFF, J. História e memória. Tradução Bernardo Leitão. Campinas: Ed. da UNICAMP, 1990.

NÉRI, A. L. Contribuições da psicologia ao estudo e à intervenção no campo da velhice. Revista Brasileira de Ciências do Envelhecimento Humano, Passo Fundo, p.69-80, jan./jun. 2004.

PARANÁ. Secretária de Estado da Educação. Diretrizes Curriculares da Rede Pública da Educação Básica do Estado do Paraná (DCE): história. Curitiba, 2008.

PESAVENTO, S. J. Palavras para crer: Imaginários de sentido que falam do passado. Nuevo Mundo Mundos Nuevos, Paris, v.6, p.6, 2006.

SILVA, C. C.; SILVA, N. R. A colcha de retalhos. 3.ed. São Paulo: Editora do Brasil, 2010.

TRILLA, J. A educação não-formal. In: ARANTES, V. A. (Org.). Educação formal e não-formal. São Paulo: Summus, 2008. v.1. p.59-89. 
ZIMERMAN, G. I. Velhice: aspectos biopsicossociais. Porto Alegre: Artes Médicas Sul, 2000. 